\title{
Physical and mental health status: A review of the Covid-19 pandemic's impact and related management strategies
}

Hazel Anika L Faco *, Rizelle Joy D Gegare, Cristine Ray P Laluna, Gresha Sheine S Larido, Julie Jill R Torino, Denise Marfe S Pedregosa, Aubrey May A Villegas and Jacqueline Abiso - Padilla

San Pedro College, Davao City, Philippines.

GSC Biological and Pharmaceutical Sciences, 2022, 18(01), 051-072

Publication history: Received on 01 December 2021; revised on 07 January 2022; accepted on 09 January 2022

Article DOI: https://doi.org/10.30574/gscbps.2022.18.1.0375

\begin{abstract}
The novel threat of the COVID-19 (Coronavirus Disease 2019) outbreak significantly affected the whole world. This pandemic has influenced the world's economic, physical, mental, and social state and well-being. There have been observable drastic changes due to the pandemic that could be destructive to the total being of an individual; thus, it is alarming. Reports show percentages of anxiety and depressive states in adults and children during the pandemic, also the physical health percentages during the pandemic. Hence, access to health support facilities should be prioritized towards improving health outcomes. This study will help give awareness and strategies that could help people shield themselves, primarily since this pandemic mainly targeted their physical and mental well-being. In this viewpoint, factors affecting the physical and mental welfare, the COVID-19 pandemic linkage to mental and physical well-being, societal states before and during the pandemic, standards on good mental and physical health, the sudden shift of situation, status of the physical and mental well-being of different individuals, and management strategies to help improve mental and physical well-being are discussed. The paper will be focusing on the state of mental and physical well-being prior to and throughout the pandemic.
\end{abstract}

Keywords: COVID-19; Physical and Mental Health; Management Strategies; Employment

\section{Introduction}

Coronaviruses are a specific type of virus that can lead to diseases, including respiratory illnesses such as common colds, Middle East Respiratory Syndrome (MERS), and Severe Acute Respiratory Syndrome (SARS). In 2019, a novel coronavirus known as the SARS-CoV-2 coronavirus was discovered by scientists in Wuhan, China. Additionally, the SARS-CoV-2 is the aforementioned newly-discovered virus, also known as COVID-19, which has caused a lot of illnesses and increased mortality in the months since its discovery. In 2020, the World Health Organization declared the occurrence of such phenomena as a pandemic [1].

According to Pierce M, et al. [2], before the pandemic dated back in the year 2014 - 2015, 2015-2016, 2016-2017, 20172018, 2018-2019, the percentage level of mental distress having 16.7\%,16.9\%, 18.2\%, 18.9\%, respectively, and during the pandemic specifically, in April 2020 the percentage level of mental anguish has increased to $27.3 \%$. A clear escalation is shown previously as the percentage indicates the level of mental distress during the pandemic increased by about $8.4 \%$. It applies to both genders, ages $16-\geq 70$ years old. The census shows a drastic increase in the levels of mental distress affecting physical health before and during pandemics, thus considered an increasing concern. Additionally, some activities could improve our physical health through doing some physical activity. According to Srivastav AK [3], in their study, four (4) categories are included in physical activity, such as vigorous and moderate physical activity or exercise, walking, and sitting. It indicates that students and professionals had 2727.3 MET-min/wk

\footnotetext{
* Corresponding author: Hazel Anika L Faco

San Pedro College, Davao City, Philippines.
} 
(Metabolic Equivalent of Task-minutes per week) of vigorous exercise before the pandemic compared to 1165.2 METmin/wk during the pandemic, which resulted in a reduction of nearly $57.3 \%$. In moderate exercises, there is a comparison between before and during the pandemic having 1994.3 MET-min/wk and 728.2 MET-min/wk, respectively, there is a decrease of about $63.5 \%$. Also, people performing walking as a physical activity decreased by about 27.4\%; before the pandemic, people spent 3088.2 MET-min/wk, while only 1255.3 MET-min/wk during the pandemic. The sitting behavior of the people was affected by the pandemic, which increased by $377.1 \%$. It shows that people spent 1255.3 MET-min/wk of sitting during the pandemic, while before the pandemic, people spent 332.9 MET$\mathrm{min} / \mathrm{wk}$ on sitting. It is evident that there was a drastic drop-in physical activity among the students and professionals during the pandemic, based on their response to the survey. The result of lockdown during the COVID-19 pandemic is detrimental to an individual's mental and physical health due to decreased daily exercise and fitness routine.

Indeed, the situation was different during the COVID-19 outbreak; people were forced to stay home for several weeks. Depression, tension, exasperation, sleeplessness, perturbation, poor focus, uncertainty, and post-traumatic stress syndrome have all been examined due to quarantine in previous epidemic outbreaks. These observations, on the other hand, are consistent with the conditions of individuals confined in solitary confinement on a particular circumstance basis [4]. Moreover, one of the primary causes of worldwide health problems is physical and mental health conditions. Factors affecting mental and physical well-being include social capital, socio-economic status, biological factors, and lifestyle habits [5]. With the problems mentioned above in this statement linked with the status of physical and mental health of an individual, there are still ways and management strategies that people can follow to ease their problems, to keep and maintain their health during these trying times. The management strategies could include engaging in physical activities outdoors, psychological techniques, relaxation techniques, social connection, faith-based practices, learning and planning, and food, alcohol, and substances. All of the mentioned management strategies will be further discussed in the latter part of this paper.

This study aspires to unravel the effects of the COVID-19 pandemic on an individual's physical and mental health, the current state of the pandemic, and the fundamental management measures employed during the pandemic. Specifically, it seeks to (1) identify the status of the society in the matter of their physical and mental health during a pandemic; (2) determine the factors that affect the society on their physical and mental health during the pandemic; (3) determine the repercussions of the occurrence of the pandemic to the people's mental and physical health, and (4) identify the significant difference of the physical and mental well-being of the society before and during the pandemic.

\section{Methods}

A well-structured literature overview is done for this article review to find reliable evidence or published literature (e.g. Up-to-date journals from databases and articles) that focus on the pre-pandemic and during pandemic societal states, the elements that influence on the well-being physically and mentally, the aftermath of COVID-19 pandemic on the health of individuals in terms of their physical and mental status according to their state of employment, and corresponding management strategies. After gathering substantial evidence, relevant data were evaluated in terms of their significance, validity, and appropriateness regarding the research topic, which will fill the gaps of the research. The manuscript is reviewed often to make suitable changes before approaching any journal database.

\subsection{The State of Good Mental and Physical Health}

Individuals' livelihoods are not the only concern that has greatly impacted the COVID-19 pandemic but also the mental and physical well-being. It is highly recognized that exercising or engaging in any physical activity is helpful for the mental as well as physical well-being [6]. It is especially effective in maintaining mind and body and preventing the harm caused by the pandemic.

Mental and physical well-being are intrinsically linked or interconnected. Multiple links exist between mental and physical health, which substantially impact individuals' demand for health care, quality of life, and other societal implications [7]. Health was well defined to be a condition of comprehensive social, mental, as well as physical being, rather than absence or lack of sickness by the WHO or World Health Organization Health was well defined as a condition of comprehensive social, mental, as well as physical being, rather than absence or lack of sickness by the WHO [8].

A condition in which an individual recognizes its potential and capabilities and even manages everyday stressors, works productively, and contributes to their community is identified as mental health [8]. In addition, having good mental health is essential to having to experience positive emotions such as love, joy, happiness, compassion, and mostly be content with life. Furthermore, building resilience is a crucial aspect of maintaining excellent mental health. This is when one has to manage life's unforeseen challenges and problems by relying on their strength and willpower [9]. Individuals 
that exhibit confidence and self-efficacy are more likely to engage in a positive personality that improves their motivation and self-esteem. Resilient people have good perspectives of themselves due to their optimistic mindset, prompting them to seek out and respond to situations positively [10]. Nonetheless, according to an article [10], stating that Mark et al., 2011 perceive the trait resilience is complex. Apart from positive beliefs, being resilient can include a variety of additional personal characteristics that can help them avoid suffering and enhance overall welfare, especially in times of uncertainty.

Physical well-being issues enhance the chances of having mental health issues and vice versa. However, just because you have a mental health condition does not indicate you will have a physical health problem [11]. Moreover, to promote physical health, physical activity is a beneficial and excellent preventative tool. Aside from significant benefits, various psychological benefits have been documented, with most research relating to anxiety and depression. Physical activity, for instance, remained to improve symptoms of depression in individuals who are suffering from it [12]. Long periods of quarantine and staying at home make it difficult for individuals to remain physically fit and active which could negatively impact or affect people's quality of life. During pandemic (COVID-19), physical activity is suggested as it has various good physical and mental health advantages [13].

Mental health is a significant determinant of physical health, having a greater impact than other health deterministic variables. Individuals' mental health may influence their decision-making processes, limiting their ability to obtain knowledge about their health, prevention, and healthcare provider quality, and thereby affecting physical health. Mental and physical well-being are linked to lifestyle choices like physical activity, smoking, drinking alcohol, and diet [5]. In most cases, COVID-19-induced lockdowns are characterized by restricted movement and disturbed food supply and accessibility. Pandemic control measures and travel limitations, in particular, may jeopardize people's ability to sustain physical activity and healthy habits, as well as their capacity to consume a broad and nutritious diet [14].

Physical symptoms might involve mental health issues. Since the body and mind are not distinct or independent, it is not unexpected that mental wellness can impact the physical health or well-being of the body and vice-versa.

\subsection{Pre-pandemic and During Pandemic Societal States}

\subsubsection{Situation before the Pandemic}

The COVID-19 pandemic is a massive catastrophic event on a worldwide scale. Individuals who are infected, those who are quarantined, hospitalized patients and their relatives and friends, as well as those who are bereaved of those who died on account of COVID-19, all have a negative effect on health. The outbreak has had an impact on not only general human issues, but it has also resulted in devastating financial and political crises in the countries affected. It was also identified as a major cause of social inequalities and inadequacy, in addition to being a threat [15]

In December of this year, it was discovered that COVID-19 had spread to the Hubei Province of Wuhan City, People's Republic of China. Symptoms of infection included severe respiratory problems including coughing and wheezing, headaches, fatigue, throat pain, mild fever, and other symptoms [16][17]. A few cases were consolidated in Egypt, Algeria, and Nigeria, among other African countries. According to reports, China has been experiencing a persistent and irresistible illness outbreak since 1949 [18]. It is a last-ditch effort because the disease has spread so quickly and with such a high level of prevalence, and efforts to stop transmission have had a significant impact on almost everyone from different countries. Prior to the WHO's proclamation of the COVID-19 Pandemic, there were reports of significant improvements in psychosocial factors awareness and the need for broader community health intervention [19]. Unfortunately, education, housing, and other structural issues that affect health, well-being, and equity have taken a long time to develop. The COVID-19 Pandemic has elevated the burden, stress, and pressure on several of the systems mentioned above [20].

\subsubsection{Current Situation of Pandemic}

Over 3.1 million more cases were recorded for the week of November 1 to 7, 2021, on the report of WHO, indicating a small upward trend of about 1\%. This week, nearly 48,000 new fatalities were reported, down 4\% from the previous week. In the WHO European Region, case and mortality rates increased, while they decreased or remained stable in other areas. As of November 7th, there had been over 249 million confirmed cases and over 5 million fatalities [21].

The Department of Education (DepEd) announced on November 9, 2021, that students in a small number of face-to-face classrooms across the country will not be subjected to the COVID-19 assessment. The Department of Health (DOH) does not approve COVID-19 testing for children, according to Education Assistant Secretary Malcolm Garma, who spoke at a press conference on Tuesday [22]. 
The Department of Health considers making the COVID-19 vaccine mandatory as a "last resort." Following the filing of a bill in the House of Representatives mandating immunization, the CDC (Centers for Disease Control and Prevention) announced in April that it was sticking to experts' advice to keep the public immunization campaign "purely voluntary." In March, eight months after the vaccine distribution commenced, about $26 \%$ of the population was fully immunized. By the end of 2021, the administration hopes to have doubled that percentage, with a goal of reaching $50 \%$ of the population by December. By the May 2022 elections, it hopes to have $70 \%$ of the population immunized, and by then, $90 \%[23]$.

\subsection{3. $\quad$ Physical and Mental Status Before and During Pandemic}

The COVID-19 pandemic has caused widespread turmoil in people's lives everywhere across the world. It has hampered almost everyone's daily activities, including those who rely on going to the gym for physical exercise. Regular home fitness workouts greatly aided people in overcoming psychological issues and fitness concerns during the lockdown. They could deal with psychological issues as well as physical health issues by performing various fitness and drills at home. It has been proven that mental health issues and excessive use of social media in one's spare time are linked. However, their self-esteem and determination to break free from their reliance on gym and other fitness devices and continue their workout routines in their respective homes significantly improved. Participants frequently listened to music while exercising [24].

In the study by Giuntella et al, at the upsurge of the pandemic, researchers documented and analyzed interruptions in physical activity, sleep, and time use among young adults, as well as the link between these disruptions and mental health issues. Physical activity disruptions are strongly linked to mental health, in an attempt to restore physical activity in a short period of time does not guarantee to improve mental health. Average daily steps dropped from 10,000 to 4,600 steps at the start of the pandemic, sleep increased by about 25 to 30 minutes per night, socialization time decreased by more than half to less than 30 minutes, and screen time more than doubled to over 5 hours per day. Between March and July 2020, the proportion of people at risk for clinical depression rose from $46 \%$ to $61 \%$. Also, when compared to the same population before the pandemic, depression rates have increased by $90 \%$ [25].

Cough, headache, and sore throat are the most common symptoms associated with poor mental health, according to COVID-19's link to mental health [26]. Throughout the pandemic, a higher-than-average proportion of young adults (ages 18-24) had anxiety or depression symptoms (56\%). Young people are more likely than other adults to report substance abuse and suicidal behavior (25\% vs. $13 \%)$ (26\% vs. $11 \%)$. Young adults were already at high risk of poor mental health and substance abuse prior to the pandemic, but many did not receive treatment. Nearly four out of ten adults in the United States reported anxiety or depressive disorder symptoms during the pandemic, a number that has remained relatively constant, up from one out of ten adults reporting similar symptoms from January to June 2019 [25].

In the July 2020 KFF (Kaiser Family Foundation) health tracking poll, many adults expressed negative effects on their well-being and mental health as a result of stress and fear about COVID-19. The health tracking poll garnered these results in percentages: $36 \%$ comprises sleeping problems, $32 \%$ is eating, $12 \%$ both increasing alcohol or substance use and deteriorating chronic illness. As the pandemic continues, critical public health actions expose a wide range of people to situations linked to weak or poor mental health, such as isolation and job loss [27].

\subsubsection{Factors Affecting Mental and Physical Well-being}

The absence of disease or illness does not solely determine happiness. A diverse combination of physical, mental, emotional, and social aspects has influenced a person's well-being. Happiness and life satisfaction are, in fact, inextricably linked to well-being -. As a result, wellness is a person's attitude toward themselves and their lives [28]. According to an article, well-being is a state of mind characterized by a sound mind, a strong sense of fulfillment, a clear understanding of the direction in life, and the capacity to cope with stress. Due to the numerous connections between mental health and chronic physical disorders, all of which have a substantial impact on the quality and status of an individual's life, usage of medical care and other services with public funding, and societal repercussions [29].

Physical well-being refers to a person's potential to live a healthy lifestyle that allows them to go about their everyday tasks without being tired or agitated. It comprises keeping one's body in excellent condition and recognizing the daily routines and behaviors that affect overall health, satisfaction, and life quality [30]. In addition, emotional, psychological, and social well-being are all part of mental well-being. It impacts how an individual thinks, feels, and acts and influences handling stress, interacting with others, and making decisions [31].

In life, there are a lot of circumstances and situations that could influence or alter the state of a person's health, such as social capital, socio-economic status, biological factors, and lifestyle habits [32]. The following factors that could affect 
the physical and mental well-being of an individual are: self-esteem, feeling loved, confidence, family breakup or loss, complex behavior, physical ill health, and forms of physical, sexual, psychological, or verbal abuse [33]. Other factors that could significantly impact mental health that may include physical health are the following: feeling of loneliness, isolation, grief and loss, domestic and family violence, bullying, unemployment, loss of business, sleeping problems, life stages due to aging, and events such as financially distressed, unemployment, death, accidents, relationship breakups, alcohol and other drug use [34]. In addition, diet, changes in physical activity, smoking, income, retirement, stress, and intellective skills would also take part as factors [32].

\subsubsection{Sudden Shift and its Effect on Physical and Mental Status}

The significant effect of changes on one's well-being and ability to function is dependent on how those individual responds to and copes with those drastic changes. Political shifts, dislocations, uncertainty, lifestyle changes, and employment changes have all been characterized as being particularly difficult for individuals to cope with and adapt to [35]. None of these changes, on the other hand, have had as large an impact on a large number of individuals and in the same way as the economic and social lockdown imposed in 2020 to contain the pandemic. This crisis, in particular, is notable for causing multi-scale changes as it extends its effect beyond the health component and poses economic, political, and social catastrophe. The interaction between multiple individual and social levels has indeed made the whole situation much more difficult to manage [36]. Some governments have used a partial or complete lockdown as a strategy for coping with the epidemic, which has a significant effect on their citizens'. It was necessary for such populations to adjust quickly not only to the unannounced casualty that could occur like job loss, illness or death, and disagreeable situations but also to the changes that were imposed on them.

Overwhelming events, social disturbance of everyday life, feeling exposed, at danger of infection, and dread of passing the disease to family and loved ones are all risk factors for mental health. Prior to this occurrence, it was shown that healthcare workers encountered tremendous stress and similar repercussions during the pandemic [37]. Throughout the isolation period of the patients, parents noticed mental and emotional distress changes in their children, including difficulties focusing on their day-to-day activities, being irritated most of the time, restlessness during daytime, anxiousness, and even anxieties [38]. The encouragement and support from the family have a stronger effect in preventing the risk of having mental health issues in Asia than in Western countries, hence having more than 6 persons and being in the same home with children are considered as protective variables - Asians prioritize family support [26].

Moreover, increased anxiety and mental anguish were quickly documented among the confined individuals [39][40], and those who are confirmed to have contracted COVID-19 or those who have symptoms that are comparable with COVID-19 [41]. In particular, the decline in the general population's mental well-being served as a notice of the severity of the constantly rising public health crisis in its early stages [42]. Individuals who are usually able to manage stressors may have been affected by the decline in their own well-being and may appear to be less capable of dealing with them during the outbreak [43]. Uncertainty and fear were also identified as essential factors in the behavioral and emotional response of individuals to the pandemic. Anxiety can be triggered by uncertainty intolerance, which can lead to maladaptive or adaptive coping mechanisms [44][45]. While maladaptive techniques may create additional distressand, in some cases, an increase in eating disorders - they also have the potential to enhance eating disorders [46] adaptive approaches help in the management of anxiety and the enhancement of self-esteem.

According to Changwon S, et al. [47], researchers discovered that COVID-19 was causing higher tension and anxiety in the majority of the subjects. Furthermore, the PSS (Perceived Stress Scale-10) results revealed that our subjects experienced moderate levels of stress. Among the consequences of the pandemic, it was also discovered that the most prominent concerns were about the individual itself and family's health issues, followed by trouble focusing. In relation to the normal stress and anxiety of college students' lives, it was indicated that COVID-19 countermeasures, such as shelter-in-place directives and social distancing practices, may have supported major changes in students' lives. For example, the great majority of individuals reported changes in social ties, owing mostly to restricted physical encounters with family and friends. Concerningly, $44 \%$ or 86 of 195 individuals reported a rise in depressed thoughts, and $8 \%$ or 16 of 195 expressed suicidal thoughts as a consequence that have caused by the crisis condition, college students' population with $3 \%$ to $7 \%$ had a mental breakdown. In addition, an online study indicated that during the pandemic, mostly college students are more afflicted by mental distress and disparity. These findings suggest that, in that way, the crucial effects of the isolated patients, patients experiencing minor psychological problems should be monitored and promoted [38]. Although our participants explicitly noted feelings of loneliness and helplessness, as well as financial and academic difficulties, other outcomes considered to be affected due to the crisis of this pandemic may potentially operate as contributors to depressed thoughts and suicide ideation. Depression is related to both troubles concentrating and changes in sleeping patterns [47]. 
The study also finds a number of coping techniques that range from adaptive to maladaptive behaviors. Denial and disengagement, two maladaptive coping practices, have been demonstrated to be major predictors of depression in young people. Acceptance and proactive activities, on the other hand, are recognized to have a favorable influence on mental health. According to our findings, the majority of our individuals engaged in maladaptive coping techniques. It is critical to identify kids' coping behaviors in order to influence the planning and design of support systems [47]. The constant dread of infection/coronavirus leads to obsessive thoughts, which leads to a person's growing closure and a reduction in social contacts [38].

Without interventions, the pandemic's devastating impact could manifest itself as an increase in horrible health behaviors such as increased alcohol and drug intake. On the other hand, exercise and greater leisure appeared to encourage individuals in embracing the pleasing changes during the initial lockdown such as increased effect in academic performance, and longer hours of sleep, while consumption of junk food and smoking was reduced [48]. Thus, identifying certain populations experiencing multiple changes together with the impact of changes regarding on their mental well-being issues might also support health-care authorities in providing and considering on which changes first to address, in that way it can prevent from mental distress can develop into a psychological problem or, in the worstcase scenario, lead to suicidal behavior [49].

Females and nurses were significantly affected by the negative effects of mental health. Frontline female nurses work at a close distance to patients for a longer period of time, which can also lead them to be physically and mentally exhausting [26]. According to the study, during the pandemic female workers with ages ranging between 26 and 40 years made up 68.7-85.5 percent of medical professionals. Furthermore, female workers are most likely to be affected by mental distress like anxiety and despair. Definitely, in the field of medical professionals, at the age of 30 years old most likely exhibit questioning themselves about their emotions, the fear about being infected or even infecting their families, compared to those at later ages. According to the WHO year 2019 and the CDC year 2020, proposed specific guidelines regarding the appropriate function of health protection with the aim of reducing mental issues symptoms in the population by trying to reduce the distress associated with professionals in the field of medical professions [38]. A study was found, based on the research of the impact on the pandemic that mainly focuses on the Asians' physical and mental health. Such an outcome may provide credence to the theory of psychological benefits derived from wearing a face mask. One of the benefits was feeling secure from infection due to perceived control [26].

\subsection{Correlation between the Pandemic Situation and the Mental and Physical Health State}

People were confronted with unexpected emotional issues in the aftermath of the epidemic, particularly those connected with sadness, anxiety, or dread. The COVID-19 contagion is a grave threat to one's bodily and emotional health [50]. The incidence of the COVID-19 pandemic, which coincided with the economic downturn, has had an adverse influence on many people's health and created plenty of problems, particularly for those who already have anxiety disorders or drug misuse issues [27]. According to a new systematic study by Wang C et al. [26], during the pandemic, perturbation, depression, post-traumatic stress syndrome, and stress have all been found to be more prevalent among the general populace and health care workers.

Indeed, studies on viruses have demonstrated that pandemic events have an emotional influence on public citizens' levels of stress and resilience. When people have health concerns, their anxieties might manifest themselves in psychological symptoms. Reports of medical supply constraints are likely to provoke feelings of anxiety and impotence, which will only exacerbate stress levels [51]. For instance, during the recent virus outbreak, 10-30\% of the population reported having major anxiety about contracting the disease. Establishments during these times, such as schools and shops, were suspended from operating; people declared increasing emotional states and psychological morbidity [52]. Females, retirees, educated and worried people, and those who had symptoms of the virus were all more likely than the general population to follow the pandemic precautionary measures, according to the study by Leung GM et al. [53]. Moreover, research about people's emotional reactions towards the Ebola virus discovered that some individuals experienced depression, worry, difficulty concentrating, and a sense of grief in these occurrences [54][55].

According to the statistics [56], the emergence of psychiatric diseases and mental welfare was recognized as the ninth (9th) most frequently researched topic during the pandemic. Several significant mental health repercussions, such as stress, concern, despair, frustration, and uncertainty, began to develop gradually throughout the onset of the COVID-19 pandemic [57]. Furthermore, generalized fear and society-wide concern are customary psychological reactions linked to the global quarantine intended to stop the COVID-19 virus from spreading. These behaviors are common during illness outbreaks and worsen as the number of new cases has risen, along with insufficient, anxiety-inducing information from the media [58]. Furthermore, there is a need to identify distressing topics relating to the health and 
socio-economic recession to detect poorly functioning processes and problematic lifestyle changes that may lead to the emergence of health disorders as the public becomes more vulnerable.

\subsubsection{Status of the Physical and Mental Well-being of Different Individuals according to State of Employment}

In order to give a clear correlation of the health outcomes of the COVID-19 pandemic on various people, physically and mentally, it may be necessary to outline them according to the state of employment in the society.

\subsubsection{Employed}

A maintained mental well-being is essential to enhance the quality of life, reduce hospital expenses, to withstand mental health problems, and strengthen societal efficiency [59]. On the other hand, physical well-being possesses the capability to carry out activities and execute communal responsibilities without any bodily restrictions and physical health problems [60]. The new 'Work from Home' concept has emerged from various working sectors and is rigidly mandated by different countries to avoid the transmission of the virus. This directive left the employees no choice but to work in the premises of their homes unprecedentedly [61]. The routines on which they are accustomed have been disturbed, which might result in physical and mental stress giving the likelihood of greater impact considering the present economic position [62]. For instance, respondents in a research study who were required to change their work time, alter schedule, and had more disturbances reported two or more recent physical or mental health problems. On the other hand, more contentment with the indoor workspace environment of respondents decreased the possibility for the recent existence of consequences on health physically and mentally [63]. The global proliferation of the COVID-19 disease has had a significant implication that could have an impact on society's overall health [64].

The crisis exacerbated when the required lockdowns and work from home continued to the extent that it impeded people's socialization [62]. As a consequence, the authors of a study about the health problem symptoms of laborers prior to and in the course of the pandemic concluded that health issues' symptoms are more manifested during the pandemic than before. Moreover, the degree of physical problems is highly exhibited during the pandemic. As evidence, Table 1 demonstrates that physical health issues of employees are more prevalent during the pandemic [65].

Table 1 Descriptive statistics and significant distinction of health issues according to physical manifestations of employees prior and during the pandemic, Adapted from Rožman and Tominc (2021) [65]

\begin{tabular}{|c|c|c|c|c|c|c|}
\hline \multirow[b]{2}{*}{ Statement $^{1}$} & \multicolumn{2}{|c|}{$\begin{array}{l}\text { Before the COVID- } \\
19 \text { epidemic }\end{array}$} & \multicolumn{2}{|c|}{$\begin{array}{l}\text { Amidst the COVID- } \\
19 \text { epidemic }\end{array}$} & \multirow[b]{2}{*}{$\begin{array}{l}\text { Mann- } \\
\text { Whitney } U \text { test }^{1}\end{array}$} & \multirow[b]{2}{*}{$\begin{array}{l}\text { Asymp. } \\
\text { Sig. } \\
\text { tailed })^{2}\end{array}$} \\
\hline & Mean & $\begin{array}{l}\text { Standard } \\
\text { deviation }\end{array}$ & Mean & $\begin{array}{l}\text { Standard } \\
\text { deviation }\end{array}$ & & \\
\hline Experiences migraines & 3.31 & 1.146 & 4.11 & 1.154 & 260032.000 & 0.000 \\
\hline Sleep pattern is complex & 3.53 & 1.099 & 4.45 & 0.891 & 219794.500 & 0.000 \\
\hline Has vertigo & 2.46 & 1.066 & 2.95 & 1.365 & 350946.000 & 0.000 \\
\hline I am sweaty & 2.47 & 1.079 & 2.78 & 1.282 & 380319.000 & 0.000 \\
\hline Sweating and chilly hands & 2.41 & 1.065 & 2.74 & 1.284 & 375449.000 & 0.000 \\
\hline Varied blood pressure & 2.63 & 1.102 & 2.90 & 1.260 & 382670.500 & 0.000 \\
\hline Experiences flu or viruses oftenly & 2.83 & 1.105 & 3.19 & 1.261 & 363967.500 & 0.000 \\
\hline Tired and exhausted often & 3.43 & 1.066 & 4.30 & 0.959 & 230936.500 & 0.000 \\
\hline Experiences stomach pains & 2.83 & 1.159 & 3.61 & 1.325 & 287657.500 & 0.000 \\
\hline Heart rate has escalated & 2.76 & 1.124 & 3.11 & 1.239 & 364151.500 & 0.000 \\
\hline I have lower back and shoulder aches & 3.47 & 1.118 & 4.17 & 1.016 & 272668.000 & 0.000 \\
\hline Experiences dyspepsia ${ }^{2}$ & 2.77 & 1.155 & 3.56 & 1.351 & 292357.500 & 0.000 \\
\hline
\end{tabular}

${ }^{1}$ These are adapted to make them concise and brief as possible; ${ }^{2}$ This test shows the comparison if there is a difference in the dependent for the independent variables; ${ }^{3} \mathrm{P}$-value that evaluates the null as opposed to an alternative which mean is not equivalent to 50 
Research about impacts on the well-being of workers operating from home during COVID-19 pandemic provided data for the comparison of physical and mental health with the affirmation that improved mental well-being is associated with improved physical well-being, such as greater physical exercises and healthy food consumption [63]. This is correlated with the study that took place across five United States states, which described that a decline of mental health is a result from the dilemma of maintaining physical activities, according to the declaration of participants [66].

Furthermore, reduced mental well-being is related to increased interruptions especially in an environment not conducive for working, such as the home. This information is affirmed by the results of the study claiming that about $64.8 \%$ of respondents revealed a recent physical health problem and roughly $73.6 \%$ of them had a new mental health problem from working at their home in the period of the pandemic [63]. A study examining the association of bodily activity and mental health gave information that at the time of the pandemic, the mental anguish scale score of the respondents increased more than before the pandemic, considering that mental distress aggravated during COVID-19 pandemic. According to Liu et al., the pandemic worsened mental health problems that resulted in mental disorders, substance abuse, and emotions of fear, stress, and anxiety. These results are in connection to worries and on being infected by the virus, anxiety when thinking about the future, and decreased communal support [66].

A study about depression in frontliners highlighted the decreased time for them for reflection and mental tasks due to their surging workload, loneliness or isolation, and solicitude exhaustion, which forecast occupational stress. In addition, the stress mentioned is an essential predictor of anxiety, insomnia, fatigue, job dissatisfaction, and plan of departure. Comparingly, more than $60 \%$ of the employees exhibit signs of depression [67]. Research finding suggests that the negative impacts of mental health issues affect both medical and nonmedical workers such that those who are assigned to high-risk areas to care for COVID-19 patients encounter more workload, hence are more likely to experience stress, depression, fatigue, and exhaustion [68].

\subsubsection{Unemployed}

The past research provided evidence that individuals without occupation will experience negative outcomes on the various factors of health and add to poorer quality of life in terms of health. In normal conditions, unemployment causes approximately a 10\% loss in quality-adjusted life years (QALY), which can be exhibited by surging problems of anxiety and depression. As evidence, mental issues were observed in $24 \%$ more of the jobless people than those who are working. Moreover, physical problems were more usual among the jobless than employed [69]. An immense unemployment [70] or temporary job loss [71] were the reverberations of the COVID-19 pandemic which complicated antecedent mental health and drug use problems and generated recent disorders for other people [70].

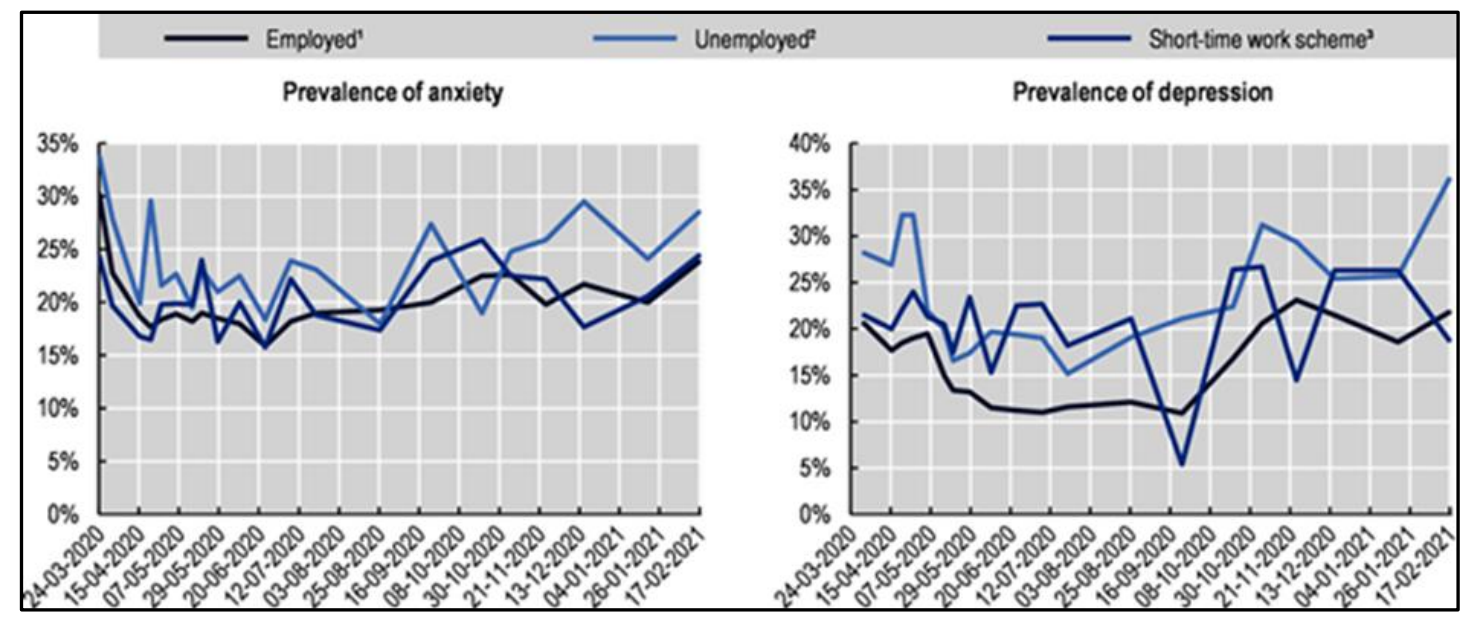

Figure 1 Anxiety and depression are more pervasive on unemployed people in France, Adopted from OECD (Organisation for Economic Co-operation and Development) (2021) [71]

Since the pandemic exacerbated the risk factors with regards to mental health issues which are unemployment and disrupted protective elements such as social connectivity, occupation, education, physical activities, and accessibility of services on healthcare, an escalating number of individuals suffering mental problems. For instance, a longitudinal study in France demonstrated that unemployed people have more possibility to encounter depression and anxiety symptoms than employed individuals (Figure 1) [71]. This is comparable to the study of Mamun et al., who claimed that the current unemployment situation has aroused the stress and anxiety levels of individuals, especially with financial instability 
[72]. As further evidence, data from research reported that the decreased accessibility to financial assets worsened the negative impacts on the health of unemployed people [73].

Unemployment during the pandemic is also correlated with physical health issues such that this connection is mediated through socializing and financial assets. In a cohort study with 2,603 respondents, individuals who are unemployed, employed but not working, and do a little work have higher possibilities of bad mental and physical health. Among the groups of respondents, the highest probability of distress was observed by those who are unemployed. Next is those who are employed but not working, those with decreased hours of work, and lastly, employed individuals [73].

A greater condition of physical health and availability of medical health care services notably decrease the likelihood of screening positive for mental illnesses. Specifically, people who did not experience any delay on medical services were $38.6 \%$ unlikely to have anxiety and $31.9 \%$ less probable to have depressive problems than the people who encountered a delay on medical services because of the pandemic. Unemployed individuals who are male, older, married, and have more children do not correspond to experiencing mental disorders while having a greater level of education does associate with a higher probability of mental disorders [74].

\subsubsection{Self-employed}

The COVID-19 pandemic has caused a large appeal for emergency funds such that in the United Kingdom, numerous self-employed people make use of short-term bank loans to continue their ways of earning. These people with insecure jobs encounter the most significant effect of job loss or the provisional closure of their corporation/s. Hence, statements of increasing emotions of depression, anxiety, and fear of post-lockdown events have been recorded from the unemployed, having income losses, and decreased social interactions as the biggest stressors [75].

This is in relation to a study that provides evidence that the self-employed confront higher mental distress due to their unsecured finances since their incomes are significantly lower and volatile- a vulnerability that aggravated during the pandemic. In addition, the results determined that economic instability instigated by the pandemic affected the selfemployed through worsening short-term mental distress [76].

In another study, the lessened work of self-employed people had a higher relationship with psychological distress than the employed people. Furthermore, self-employment itself was not notably in connection with psychological distress, which the results have shown. Instead, the financial difficulties generally were positively correlated to one's mental distress. These difficulties, the actual reduction of work, and lessened revenues, which are amplified due to the global fear of the pandemic, have negative impacts on self-employed individuals' well-being [77].

In research organized in Zambia, a developing country, about the impacts of lockdown due to COVID-19 to self-employed women, participants' narratives confirmed that they are not only physically affected by the pandemic but also psychologically. They experienced mental trauma because of anxiety and depression brought by financial problems since they revealed the inadequacy of food due to business shutdowns. The complications of getting food materials were intensified by the disobliging government. Moreover, the fear that their children might contract the virus has led to stress. The pandemic also caused difficulties in health services and transport networks such that there are reports about insufficient access to services for reproductive health, maternal health, and chronic diseases. Hence, Ornell et al., concluded that these situations that led to mental problems may put the women of Zambia with financial constraints to poverty since addressing psychological illness is expensive [78].

\section{Discussion}

In the study by Panchal et al. [27], the COVID-19 pandemic, as well as the decrease in the economy, has a detrimental impact on the mental health of people, along with other problems to those that already are suffering from illnesses caused by drug problems and other factors.

\subsection{Reports on Perturbation and Depression on Various Individuals during the Pandemic}

Based on the aforementioned data, there are various findings concerning the relevance of COVID-19 on an individual's health status, physically and mentally, which will be provided comprehensively. Relevant results have been provided as a result of the Kaiser Family Foundation's (KFF) through a pulse survey made to be able to obtain data on the influence of the pandemic in people, along with specifics on the same aspect but recorded before the pandemic:

According to the research, COVID-19-related repercussions, involving the closure of schools and the loss of wages, are being experienced by young adults, which may lead to a decline in mental health. Throughout the course of the 
pandemic, there have been increased reports on young adults, aging from 18-24 years old, who have reportedly experienced the said illnesses, garnering $56 \%$ of the data. Young adults are then said to be more likely than other adults to have been exposed to drug use, $25 \%$, and $13 \%$, respectively, and suicide ideation, $26 \%$ compared to $11 \%$. Therefore, there is enough supporting data indicating that adults of the said age range are already at the risk of having poor mental stability, including drug usage, even prior to the pandemic; many still decided not to obtain treatment despite its existence.

Average Share of Adults Reporting Symptoms of Anxiety Disorder

and/or Depressive Disorder, January-June 2019 vs. January 2021

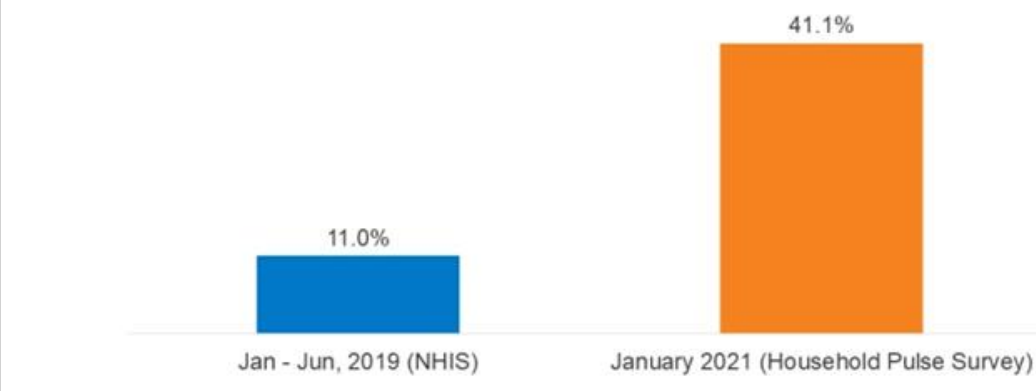

Figure 2 Percentage difference between adults having recorded perturbation and symptoms of depression amidst the COVID-19 Pandemic. Adopted from Panchal et al. (2021) [27]

\subsection{Mental Illness Prevalence and Related Data on Pandemic-Related Substance Use}

\section{Share of Adults Reporting Symptoms of Anxiety or Depressive Disorder During the COVID-19 Pandemic}

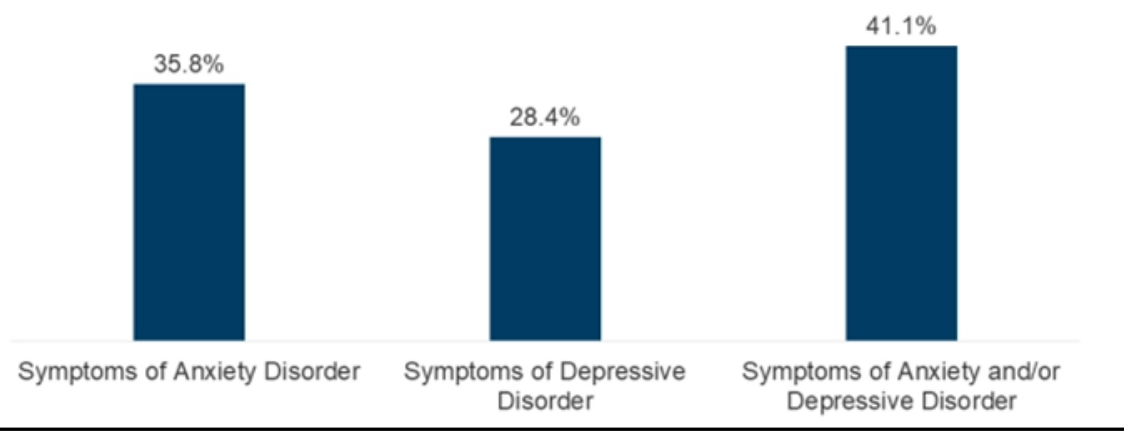

Figure 3 Percentage Showing Percentages of Patients with Mental Illnesses Throughout the COVID-19 Pandemic. Adopted from Panchal et al. (2021) [27]

Throughout the duration of the whole pandemic, concerns about the mental stability and drug misuse have risen, particularly among adults, involving their thoughts to commit suicide. Anxiety and/or depressive disorder symptoms were reported by $41 \%$ of people in January 2021 (Figure 3), a figure that has been generally steady since spring 2020. According to June 2020 research, 13\% of these people had a report for increase in drug usage, while a notable $11 \%$ of adults were able to encounter suicidal thoughts, especially that this may worsen due to the pandemic. Deaths due to drug overdose were also notably higher from March to May 2020, as it is pinned upon the onset of pandemic-related lockdowns, according to 2020 statistics previously reported.

\subsection{COVID-19-Reported Percentages on Mental Disorders}

When data is being compared to those of older ages, there is a relevant case of young adults ranging from 18 to 24 years of age having experienced symptoms of mental disorders throughout the pandemic according to the KFF study of the Household Pulse Survey (Figure 4). Prior research dating from June 2020 revealed kindred results for these young adults when it is being compared to people of different ages, which might be related to the graph above. Drug abuse and suicidal ideation are more common among young adults, according to the poll, had $25 \%$ of them disclosed that they 
have decided to start or intensify their use of drugs (causing misuse) in the course of the pandemic, along with $26 \%$ of these young adults reporting that they have encountered increased thoughts on committing suicide. Although these young adults were already reporting high risks of having poor mental headspaces with drug misuse, many of them are still not obtaining the treatment they need in the first place.

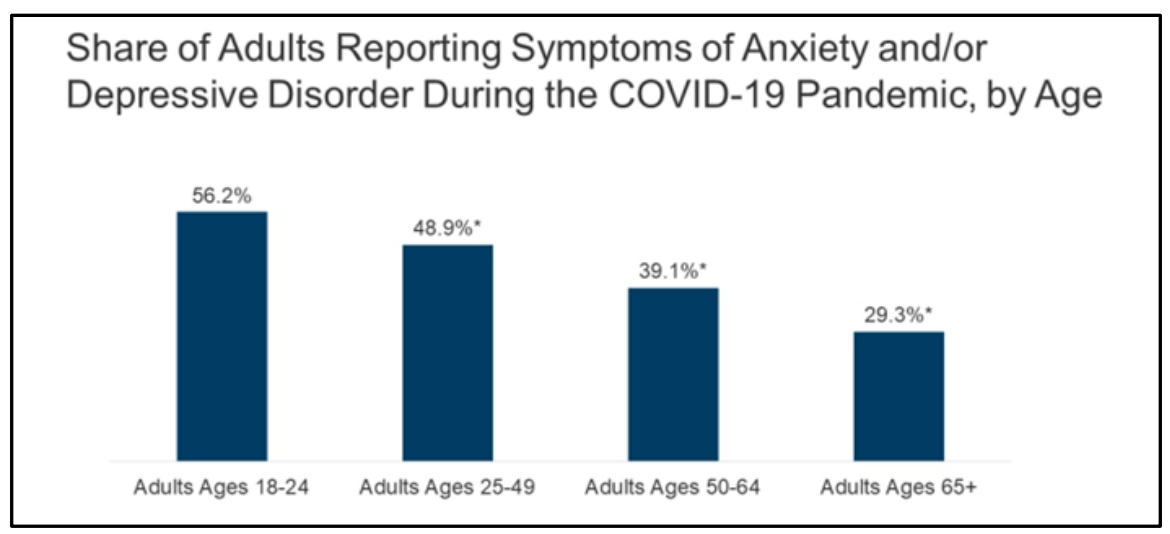

Figure 4 Percentage Differences on Adults that Possess Mental Health Disorders During the COVID-19 Pandemic. Adopted from Panchal et al. (2021) [27]

\subsection{COVID-19-Related Job Insecurity among Adults}

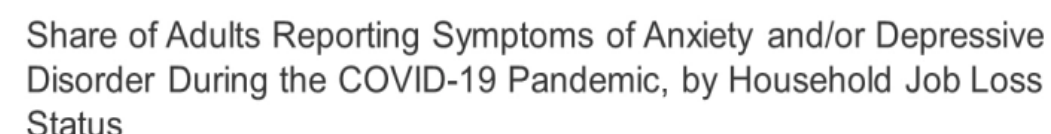
Status

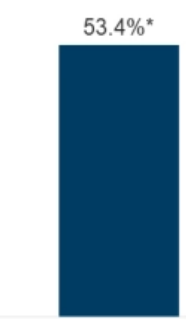

Household Job Loss Since March 13, 2020

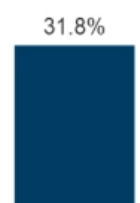

No Household Job Loss Since March 13,2020

Figure 5 Relevant percentage data on adults with mental disorders due to job insecurity that is COVID-19 pandemicrelated. Adopted from Panchal et al. (2021) [27]

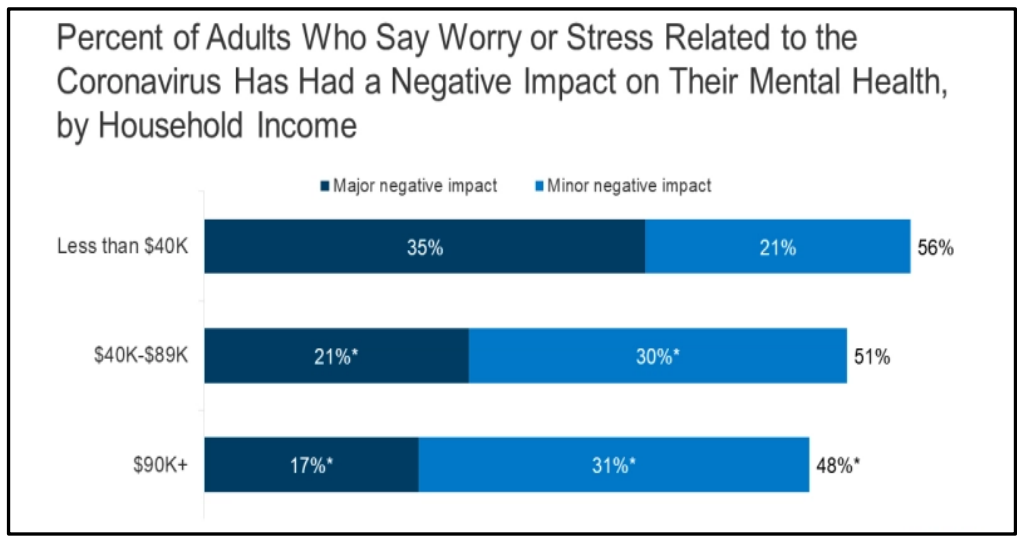

Figure 6 Relevant percentage data on adults and their COVID-19 pandemic-induced job insecurity's negative impact on their mental health. Adopted from Panchal et al. (2021) [27] 
People who have lost their livelihood due to the pandemic were said to have more perturbation cases, even depression symptoms in comparison to adults who are still working amidst the pandemic, ranging from 53-32\% sequentially. At the same juncture, according to a poll conducted in December of 2020, families that have family members experiencing any form of income instability were recorded to have believed that the current pandemic impacted their mental stability negatively. The addition of worry and despair, job loss may have extra unfavorable mental health repercussions, such as substance use problems. High unemployment rates were also linked to an upsurge in suicides during the last recession.

Finally, throughout this pandemic, KFF Health's tracking surveys have revealed that lower-income families were susceptible to having decreased status mentally due to dread or worry by the COVID-19 pandemic. As a result, by December 2020, 35 percent of these persons who are earning less than $\$ 40,000$ will have seen a severe decrease in mental health. In comparison, 21 percent of the individuals who reportedly earn more than $\$ 40,000$ and $17 \%$ of those earning $\$ 90,000$ or more are of higher mental stability.

\subsection{Parent-Child COVID-19-Related Data}

Share of Adults in Households with Children Under the Age of 18 Who Report Symptoms of Anxiety and/or Depressive Disorder During the COVID-19 Pandemic, by Gender

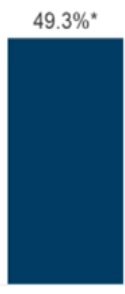

Women

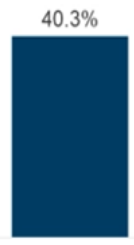

Men

Figure 7 Data through a bar graph comparing the COVID-19 leverage on both sexes with varying mental statuses. Adopted from Panchal et al. (2021) [27]

The importance of mental status stability for both the parents and their children, explicitly women is stressed, especially when they are dealing with recurring difficulties such as the closure of schools and the lack of childcare support. Women who have children are prone to melancholy and are more worried than men who have children. Apart from the aforementioned circumstance, women are consistently reported to have greater rates of anxiety and sadness than men in general.

\subsection{COVID-19 Pandemic-Related Effects on the Minor Communities}

Share of Adults Reporting Symptoms of Anxiety and/or Depressive Disorder During the COVID-19 Pandemic, by Race/Ethnicity

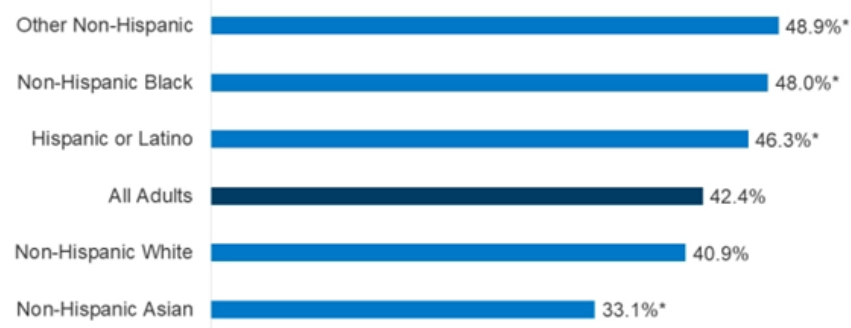

Figure 8 Mental Disorder Symptoms from Various Minor Communities. Adopted from Panchal et al. (2021) [27]

COVID-19 also has vividly harmful impacts on the minorities. In comparison to non-Hispanic White persons, black adults that are non-Hispanic and adults of Hispanic and Latino origins were said to have exhibited mental disorder symptoms. Historically, it is not new to the public that these individuals are those that have trouble accessing healthcare, may it be caused by restriction, or by mere discrimination against their races. 


\subsection{Management Strategies to Help Improve Mental and Physical Well-being during Pandemic}

\subsubsection{Outdoors and Physical Activities}

Exercise, walking, and yoga are among the frequent management strategies mentioned when it comes to improving the well-being of an individual during the course of the COVID-19 pandemic lockdown. Various studies [79-81] have shown that engaging in exercise, as a health-promoting coping strategy, was associated with psychological well-being. Finlay et. al [80] determined that there has been a significant shift from exercising in gyms to home-based and outdoor exercise through the utilization of exercise applications and online classes. The study also observed increased physically distant exercise engagement such as cycling, dancing, going fishing, pilates, playing golf, running, tai chi, and weightlifting. Moreover, exercise was the most helpful in the management of emotional burdens and its consequences caused by the pandemic, and anxiety [82]. Further, activities such as walking, hiking, yard work, and biking have been increasingly appreciated as easy access to the outdoors; and that being outside was described as therapeutic [83]. Particularly, a study conducted in an urban area in Japan [84] determined that older adults who regularly walked to maintain their mental and physical health experienced better well-being during their community lockdown than those who did not. Walking outdoors was also found to alleviate stress and anxiety [83].

On the other hand, yoga is the main support when it comes to improving well-being, overall health, and disease risk reduction. Participants in a certain study by Bartos LJ et. al [85] acknowledged the effectiveness and usefulness of yoga, coupled with meditation, during stressful circumstances and lockdown demands brought about by the pandemic. In like manner, an original research study [86] found out that individuals who practice yoga reported superior physical strength and endurance compared to the non-Yoga individuals who also appeared to have higher levels of anxiety and fear. Also, those who practice yoga reported good coping abilities. Correspondingly, the frequency of yoga practice has a positive association with higher levels of mental well-being, highlighting meditation and regular yoga practice's role in the improvement of mental well-being in the time of the current pandemic [83].

\subsubsection{Psychological Techniques}

Some of the common psychological techniques that became prominent in increasing motivation for activity during quarantine time are cognitive restructuring, mental contrasting, and psychoeducation. The cognitive restructuring aims to achieve a balanced way of thinking in individuals, therefore freeing them from overly negative interpretations of certain events [87]. In line with this, Morales-Rodriguez [88] ascertained that cognitive restructuring, after emotional expression and problem-solving, was the third most used strategy in facing the consequences of confinement and situations prompted by the pandemic.

Mental contrasting as a reality-bound and solution-focused practice, helps individuals achieve unwavering motivation despite being faced with big life challenges, thus allowing control in behaviors for goal pursuit and managing emotions [89]. It directly addresses an individual's feared feature in such a way that the perceived fear will be unveiled as unreasonable and unproportioned to the actual probability of being harmed [90]. Additionally, mental contrasting, as a self-regulation strategy that helps commitment to a goal that involves imagining the desired future and contrasting it with the current state, has been shown to have positive effects as a physical and mental health intervention across different life domains, age and culture [87][89-90]. Intervention studies, specifically by Oettingen G et. al [91] attest that mental contrasting, a metacognitive strategy, can help in regulating goal pursuits autonomously where individuals can have control of their everyday life and continuing development.

Likewise, psychoeducation increases an individual's awareness of the benefits of physical activities and encourages them to make lifestyle changes [92]. In a study conducted by Hood et. al [93], psychoeducational courses were found to increase mental well-being in a relatively cost-effective way among students during lockdown restrictions in early 2020 , hence producing beneficial effects at a time of collective stress and anxiety. Several studies also show that psychoeducation therapy brings about better results in patients, specifically improvement in self-efficacy [94-95].

\subsubsection{Relaxation Techniques}

Mindfulness-based stress reduction (MBSR), a potential technique that makes an individual become mindful of maladaptive thoughts and emotional responses. The practice allows individuals to implement more objective and productive thoughts on purpose that further enable them to have increased control over their responses to particular events, therefore reducing feelings of anxiety, depression, and helplessness [96]. Several studies reported the benefits of MBSR in managing psychological sufferings due to the suspension of in-person meetings at the start of the pandemic [97-99]. In particular, an evaluation study [101] that utilized the MBSR program for 8 weeks during the initial total pandemic lockdown in Italy elucidated that MBSR training is helpful in anxiety and stress reduction, and improvement of mindfulness skills among the female sample population. It was expounded that the previously mentioned positive 
outcomes were majorly influenced by non-reactivity, the capacity to avoid reacting to negative thoughts and emotions but instead realize their existence [100], as the protective factor from stress. Significantly, MBSR is positively associated with improved personal growth, positive relations, physical well-being, purpose in life, and self-acceptance. The finding of the study suggested that MBSR training is capable of supporting the psychological well-being of women during unprecedented events like the lockdown [101].

Breathing exercises, meditation, and practice of mindfulness and patience are also strategies that help older people stay calm and manage their stress. Participants in Finlay et al. study [80] described finding mindfulness and meditation in books, websites, television shows, podcasts, and, transcendental meditation for those who were highly experienced when panicking and worry began. Similarly, in Smirmaul et. al study [102], the promotion of relaxation response was found to be one of the effective strategies in stress management. Such relaxation responses are specifically obtained through breathing, guided imagery, meditation, tai-chi, yoga, and related techniques. Additionally, mindfulness and relaxation were found to be helpful coping strategies in the time of the pandemic [103]. Incorporating relaxation and mindfulness in tinnitus intervention are also repeatedly proven to be effective in reducing tinnitus severity [104-105].

\subsubsection{Social Connection}

Connecting with other people in-person and virtually was a frequent coping management strategy during the pandemic lockdown [79-80][106]. In a Canadian research study by Logel et. al [107], which was done to provide evidence on the best coping techniques during the pandemic to help colleges support their students better, maintaining social connections resonated with at least $45 \%$ of the sample population. Their data shows that only recommendations of social connection projected significant well-being outcomes out of a comprehensive list of coping strategies used by students, thus highlighting the importance of social support and connection in times of stress. The findings of the study further suggest that colleges may greatly support the students' well-being by providing opportunities that allow them to associate with themselves and with other people who are not associated with the college such as family and old friends. Additionally, most participants in a UK (United Kingdom) study highlighted that they have been actively socializing more with their loved ones as a coping mechanism with the pandemic. They also ascertained that socializing was very helpful in lessening the impacts of the pandemic and how beneficial it was to their mental health, mirroring the significance of social activities and connection to people's mental health during the pandemic [108]. During the pandemic, family support - the only source of support at times of strict lockdown, especially in Italy - in particular, was linked to fewer anxiety and depressive symptoms [109].

Social connections also do not have to be in-person. As daily face-to-face contact with other people has been limited and restricted, during the existing pandemic, individuals with enough resources turn to non-face-to-face communication such as texting, phone calls, and social media to maintain physical and mental health. With media connectedness, participants engaging with others via various media and the internet were seen to be more engaged in coping strategies that make them occupy themselves and actively maintain their health [110]. This finding is supported by past research by Kaniasty [111] who pointed out that in times of stress and trauma, social connection and support are both important for the well-being of the people. In addition, social connectedness underlies healthier lifestyle choices and adaptive responses to numerous stressors, especially after the pandemic started [112].

\subsection{5. $\quad$ Faith-Based Practices}

People bring different habits when faced with a crisis. Some engage or turn to devotional rituals, services, and religious communities, proving that religious coping is readily available and is more familiar to people who are religiously active prior to the crisis. Moreover, knowing, believing, and utilizing Scriptures and frequent church attendance are the significant elements of coping and protection against anxiety and worrying in African-American Christian communities [113]. Correspondingly, African-American women breast cancer survivors who are at a high risk of mortality generally rely on spirituality practices to cope up with the stress of cancer survivorship and the pandemic. With the limited access to traditional faith-based practices imposed by strict social distancing, efforts on redirecting cancer survivors to online worship services enabled them to overcome poor mental health outcomes and increasing levels of stress due to loneliness and social isolation. Listening to gospel music has also become their source of comfort and strength, and reading Biblical text provided them with additional sources for relieving anxieties and fears [114].

Locally, in the Philippines, faith-based organizations and community connection like the Church is identified as a positive coping strategy for social workers. It was noticeable that even in the rise of the pandemic crisis, Catholic ordinations had not reduced. In particular, in the news of a recent ordination in October of 2020 in the province of Southern Leyte, physical church attendance has intensified at the excitement of faithful locals [115]. Attendance to holy mass on radio, television, and online among older Filipinos has also increased several fold since the unprecedented crisis began in early 2020 [116]. In addition to this, reliance and belief in religion are in congruence with existing 
evidence, asserting that religion is a vital coping strategy among older adult populations. Religion then, as a coping strategy, provides support and ameliorates distress [117].

\subsubsection{Learning and Planning}

During the pandemic lockdown, people engaged in non-work-related activities like starting and learning new skills, hobbies, or routines to improve personal and/or professional skills as coping strategies [107,118]. According to TengCalleja M et. al [119] found that employees' coping behaviors in mitigating the effect of the pandemic include attending webinars, continuing education, and fostering professional development, among others. Similarly, learning foreign languages, musical instruments, taking online courses, and gardening are among the easy coping strategies practiced among older adults, helping them keep their body and mind busy, and enjoy a sense of control, progress, and accomplishment [80].

Planning, on the other hand, is among the top 3 of most often used coping strategies of Polish students during the pandemic - together with acceptance and seeking emotional support [120]. Making long-term plans, estate planning, contingency plans, and strategically thinking about the future, like planning events and trips after the pandemic ends, were considered as coping management responses to the lockdown [80]. Additionally, planning has been favorable in increasing the confidence and coping of young adults with self-isolation [121]. At the same time, planning as an engagement coping technique has moderate effects on the symptoms of stress and distress on quality of life [122].

\subsubsection{Food, Alcohol, and Substances}

Among international population studies, a big percent of responders have been reported to deal with stress by eating, and exhibit increased caloric/salty food intake, unhealthy food, and consumption of alcohol since the pandemic started [123-125]. One of the most well-known consequences of the pandemic was confinement which allowed for the exploration of food by seeking out new stimuli in food. Specifically, several studies [126-129] have similarly found out a strong association between emotional eating and elevated levels of anxiety, loneliness, and stress. Emotional eating is referred to as the desire of eating food as a response to ill feelings or experiences and stress. Some of the leading causes for such coping strategies are negative feelings that include anxiety, stress, and depression [126]. An Italian research study by Di Renzo L et. al [127], addressing emotional eating among 602 individuals with ages ranging from 18-79 years old, ascertained that more than half of the participants have increased food intake in order to feel better. They also regard food as a coping response to anxious feelings, depressed moods, and exhaustion with tachycardia and breathing difficulties. Similarly, emotional eating is also very common among young women in Saudi Arabia, with almost one in two women identifying themselves as emotional eaters [128]. Also, in an American study, high association of stress levels due to COVID-19 and high levels of eating to cope, added sugar intake, food addiction symptoms, and drinking frequency were reported, indicating that subjective stress at the individual level may have exacerbated the symptoms [129]. Indeed, the pandemic has clearly exhibited that eating, an emotion-based coping strategy, is a significant avoidant management strategy that aids in improving the mental health of individuals, particularly women.

Apart from eating, maladaptive coping strategies like drinking alcohol and substance use are utilized. Alcohol consumption, even though not recommended and is unsafe, is rarely used by individuals in tolerating the burden of social isolation, negative emotions, and stress [130]. During the start of the pandemic lockdown, engagement in substance use like cannabis, cigarettes, and vaping was found to be prevalent among Canadian youth [131]. Considering that individuals respond differently to stressful events, some described alcohol consumption as a way to relax, enjoy and just "get drunk" while substance use was practiced for relaxation, calming anxiety, elevating their mood, and to feel better [80].

\section{Conclusion}

The COVID-19 pandemic, even without having the need to say, has both short and deep-rooted repercussions for mental disorders and misuse of drugs, involving the persons in jeopardy of being able to develop or exacerbate mental decline, as well as those who face barriers to treatment. Due to this, COVID-19 vaccines are being administered in phases across the world, perhaps heralding the end of the pandemic.

However, due to the challenges associated with vaccinations across the world - from those that refuse to be vaccinated to those with the dire need to be vaccinated - along with further solutions executed to mitigate the pandemic, there have been continual delays in its mitigation as a whole, not only in specific countries but all throughout the world.

Despite the linkage of rising cases and mortality to the novel coronavirus cease, policymakers will need to be able to know details that this increase of demand for mental health and substance use services will still persist without being 
linked to the pandemic. The importance of continuing to analyze and improve policies implemented during the epidemic must be highlighted, especially because everything has already been damaging to people's well-being.

When it comes to prioritizing people's well-being, there will always be a need to also put the limelight on the concerns of people physically, as various stressors have forced them to navigate themselves into unhealthy habits in the hopes of being lightened by the comfort these vices provide. As a result, efforts should be made to advise these patients on the consequences of their choices if they agree to undergo therapy or are persuaded to participate in such a venture to improve their health results.

Finally, access to various mental and emotional health support facilities should be prioritized, acknowledging the reality of illnesses in people that may or may have not manifested physically but are affecting their professional performance. Instead of exacerbating the mental health taboo, varied discussions on mental health issues across the world should be the focus of change toward improved health outcomes.

\section{Compliance with ethical standards}

\section{Acknowledgments}

The researcher would like to thank their professor Mrs. Jacqueline Abiso-Padilla and San Pedro College for their support.

\section{Disclosure of conflict of interest}

The authors declare that there is no conflict of interest.

\section{References}

[1] Coronavirus disease 2019 (COVID-19) [Internet]. Mayoclinic.org. 2021.

[2] Pierce M, Hope H, Ford T, Hatch S, Hotopf M, John A, et al. Mental health before and during the COVID-19 pandemic: a longitudinal probability sample survey of the UK population. Lancet Psychiatry [Internet]. 2020; 7(10): 883-92.

[3] Srivastav AK, Sharma N, Samuel AJ. Impact of Coronavirus disease-19 (COVID-19) lockdown on physical activity and energy expenditure among physiotherapy professionals and students using web-based open E-survey sent through WhatsApp, Facebook and Instagram messengers. Clin Epidemiol Glob Health. 2021; 9: 78-84.

[4] Ramiz L, Contrand B, Rojas Castro MY, Dupuy M, Lu L, Sztal-Kutas C, et al. A longitudinal study of mental health before and during COVID-19 lockdown in the French population. Global Health [Internet]. 2021; 17(1): 29.

[5] Ohrnbergera J, Ficherab, E and Suttona, M. The relationship between physical and mental health: A mediation analysis [Internet]. Sciencedirect.com. December 2017.

[6] Sallis JF, Pratt M. Physical activity can be helpful in the coronavirus pandemic [Internet]. America Walks. 2020.

[7] Canadian Mental Health Association. Connection between mental and physical health. Canadian Mental Health Association: Mental Health for All. 2016.

[8] WHO. Mental health: Strengthening our response [Internet]. World Health Organization. 2018.

[9] Good mental health [Internet]. healthdirect. Healthdirect Australia. 2021.

[10] Mak WW, Ng IS, Wong CC. Resilience: Enhancing Well-being through the positive cognitive triad. Journal of Counseling Psychology. Oct 2011; 58(4): 610.

[11] Physical Health and Mental Health [Internet]. Mental Health Foundation. 2021.

[12] Kim YS, Park YS, Allegrante JP, Marks R, Ok H, Cho KO, Garber CE. Relationship between physical activity and general mental health. Preventive medicine. 1 Nov 2012; 55(5): 458-63.

[13] Dwyer MJ, Pasini M, De Dominicis S, Righi E. Physical activity: Benefits and challenges during the COVID-19 pandemic. Scandinavian journal of medicine \& science in sports. Jul 2020; 30(7): 1291.

[14] Matsungo TM, Chopera Effect of the COVID-19-induced lockdown on nutrition, health and lifestyle patterns among adults in Zimbabwe. BMJ Nutrition, Prevention \& Health. Dec 2020; 3(2): 205. 
[15] C Huang, Y Wang, X Li, L Ren, J Zhao, Y Hu, L Zhang, G Fan, J Xu, X Gu, Z Cheng Clinical features of patients infected with 2019 novel coronavirus in Wuhan, China Lancet. 2020; 497-506.

[16] YC Wu, CS Chen, YJ Chan. Overview of the 2019 novel coronavirus (2019- nCoV): the pathogen of severe specific contagious pneumonia (SSCP) J. Chin. Med. Assoc. 2020; 217-220.

[17] NP Shetti, RK Srivastava, S Sharma, S Basu, TM Aminabhavi. Invasion of novel coronavirus (COVID-19) in Indian territory Sensors Int. 2020; 10012.

[18] World health organization: coronavirus disease 2019 (COVID-19) situation report-47 World Health Organization, Geneva.

[19] Shi Zhao, Qianyin Lin, Jinjun Ran, Salihu S. Musa, Guangpu Yang, Weiming Wang, Yijun Lou, Daozhou Gao, Lin Yang, Daihai He, Maggie H. Wang Preliminary estimation of the basic reproduction number of novel coronavirus (2019-nCoV) in China, from 2019 to 2020: a data-driven analysis in the early phase of the outbreak Int. J. Infect. Dis. $2020 ; 7$.

[20] Miller C, Chandra A. Understanding our culture of health before the pandemic can help us improve it afterward [Internet]. Rand.org. 2021.

[21] Weekly epidemiological update on COVID-19 - 9 November 2021 [Internet]. Who.int.

[22] Magsambol B, Tantuco V, Hapal DK, Chua H, Cabal K, Paris J, et al. COVID-19 pandemic: Latest situation in the Philippines - November 2021 [Internet]. Rappler. Rappler. 2021.

[23] Tomacruz S. DOH open to mandatory COVID-19 vaccination as "last resort" [Internet]. Rappler. Rappler. 2021.

[24] Kaur H, Singh T, Arya YK, Mittal S. Physical Fitness and Exercise during the COVID-19 Pandemic: A Qualitative Enquiry. Frontiers in Psychology [Internet]. 29 Oct 2020; 11.

[25] Giuntella O, Hyde K, Saccardo S, Sadoff S. Lifestyle and mental health disruptions during COVID-19. Proceedings of the National Academy of Sciences [Internet]. 10 Feb 2021; 118(9): e2016632118.

[26] Wang C, Tee M, Roy AE, Fardin MA, Srichokchatchawan W, Habib HA, Tran BX, Hussain S, Hoang, MT, Le XT, Ma W, Pham HQ, Shirazi M, Taneepanichskul N, Tan Y, Tee C, Xu L, Xu Z, Vu GT, Zhou, D. The impact of COVID-19 pandemic on physical and mental health of Asians: A study of seven middle-income countries in Asia. PLOS ONE. $2021 ; 16(2):$ e0246824.

[27] Panchal, N, Kamal, R, Cox, C, Garfield, R. The Implications of COVID-19 for Mental Health and Substance Use [Internet]. KFF. 2021.

[28] Wellbeing [Internet]. Gov.au. 2020 [cited 2022 Jan 12]. Available from: https://www.betterhealth.vic.gov.au/health/healthyliving/wellbeing

[29] Connection Between Mental and Physical Health [Internet]. Cmha.ca. [cited 2022 Jan 12]. Available from: https://ontario.cmha.ca/documents/connection-between-mental-and-physical-health/

[30] Schwartz KD, Exner-Cortens D, McMorris CA, Makarenko E, Arnold P, Van Bavel M, et al. COVID-19 and Student Well-Being: Stress and Mental Health during Return-to-School. Canadian Journal of School Psychology [Internet]. 2021 Mar 18 [cited 2022 Jan 12];36(2):166-85. Available from: https://journals.sagepub.com/doi/full/10.1177/08295735211001653.

[31] Leigh H. What is mental health? In: Genes, Memes, Culture, and Mental Illness [Internet]. New York, NY: Springer New York. 2020; 141-53.

[32] Davis T. What is well-being? Definition, types, and well-being skills. Psychology Today [Internet]. 2 Jan 2019.

[33] Factors affecting mental health - Can We Talk [Internet]. Canwetalk.ca. 2016.

[34] Factors that can affect your mental health [Internet]. Com.au. 2019.

[35] Brammer LM. Coping with life transitions. Int. J. Advancement Counsel. 1992; 15: 239-253.

[36] Marks SR. Durkheim's Theory of Anomie. Am. J. Sociol. 1974; 80: 329-363.

[37] Shaukat N, Ali DM, Razzak J. Physical and mental health impacts of COVID-19 on healthcare workers: a scoping review. International Journal of Emergency Medicine [Internet]. 20 Jul 2020; 13(1).

[38] Saladino V, Algeri D, Auriemma V. The Psychological and Social Impact of Covid-19: New Perspectives of WellBeing. Frontiers in Psychology [Internet]. 2 Oct 2020; 11. 
[39] Bao Y, Sun Y, Meng S, Shi J, Lu L. 2019-nCoV epidemic: Address mental health care to empower society. Lancet. 2020; 395: e37-e38.

[40] Rodríguez-Rey R, Garrido-Hernansaiz, H, Collado S. Psychological Impact and Associated Factors during the Initial Stage of the Coronavirus (COVID-19) Pandemic among the General Population in Spain. Front. Psychol. 2020; 11: 1540.

[41] Choi EH, Hui BH, Wan EYF, Kwok JYY, Tam THL, Wu C. COVID-19 and Health-Related Quality of Life: A Community-Based Online Survey in Hong Kong. Int. J. Environ. Res. Public Health 2021; 18: 3228.

[42] WHO. Policy Brief: COVID-19 and the Need for Action on Mental Health; World Health Organization: Geneva, Switzerland. 2020.

[43] Rettie H, Daniels J. Coping and tolerance of uncertainty: Predictors and mediators of mental health during the COVID-19 pandemic. Am. Psychol. 2020.

[44] Zheng Z, Han W, Li Y, Wang D, Gu S, Wang F. The Mediating Effect of Coping Style in the Relationship between Depression and Disordered Eating Among Chinese Female Undergraduates. Front. Psychol. 2020; 10.

[45] Bemanian M, Mæland S, Blomhoff R, Rabben ÅK, Arnesen EK, Skogen JC, Fadnes, LT. Emotional Eating in Relation to Worries and Psychological Distress Amid the COVID-19 Pandemic: A Population-Based Survey on Adults in Norway. Int. J. Environ. Res. Public Health. 2021; 18: 130.

[46] Savitsky B, Findling Y, Ereli, A.; Hendel, T. Anxiety and coping strategies among nursing students during the COVID-19 pandemic. Nurse. Educ. Pract. 2020; 46: 102809.

[47] Son C, Hegde S, Smith A, Wang X, Sasangohar F. Effects of COVID-19 on College Students' Mental Health in the United States: Interview Survey Study. Journal of Medical Internet Research [Internet]. 3 Sep 2020; 22(9): e21279.

[48] Godinic D, Obrenovic B. Hudaykulov, A. Effects of Economic Uncertainty on Mental Health in the COVID-19 Pandemic Context: Social Identity Disturbance, Job Uncertainty and Psychological Well-Being Model. Int. J. Innov. Econ. Dev. 2020; 6: 61-74.

[49] Knell G, Robertson MC, Dooley EE, Burford K, Mendez KS. Health Behavior Changes During COVID-19 Pandemic and Subsequent "Stay-at-Home" Orders. Int. J. Environ. Res. Public Health. 2020; 17: 6268.

[50] Qiu J, Shen B, Zhao M, et al. A nationwide survey of psychological distress among Chinese people in the COVID-19 epidemic: implications and policy recommendations. Gen Psychiat. 2020; 33(2): e100213.

[51] Xiang YT, Yang Y, Li W, et al. Timely mental health care for the 2019 novel coronavirus outbreak is urgently needed. Lancet Psychiatry. 2020; 7(3): 228-9.

[52] Van Bortel T, Basnayake A, Wurie F, et al. Psychosocial effects of an Ebola outbreak at individual, community and international levels. Bull WHO. 2016; 94(3): 210-4.

[53] Leung GM, Lam TH, Ho LM, et al. The impact of community psychological responses on outbreak control for severe acute respiratory syndrome in Hong Kong. J Epidemiol Comm Health. 2003; 57(11): 857-63.

[54] Sim K, Chan YH, Chong PN, et al. Psychosocial and coping responses within the community health care setting towards a national outbreak of an infectious disease. J Psychosom Res. 2010; 68(20): 195- 202.

[55] Mohammed A, Sheikh TL, Gidado S, et al. An evaluation of psychological distress and social support of survivors and contacts of Ebola virus disease infection and their relatives in Lagos, Nigeria: a cross sectional study- 2014. BMC Public Health. 2015; 15: 824.

[56] Tran BX, Ha GH, Nguyen LH, Vu GT, Hoang MT, Le HT, et al. Studies of Novel Coronavirus Disease 19 (COVID-19) Pandemic: A Global Analysis of Literature. International Journal of Environmental Research and Public Health. $2020 ; 17(11): 4095$.

[57] Duan L, Zhu G. Psychological interventions for people affected by the COVID-19 epidemic. Lancet Psychiatry. 2020; 7: 300-2.

[58] Maunder R, Hunter J, Vicent L, Bennett J, Peladeau N, Leszcz M, et al. The immediate psychological and occupational impact of the 2003 SARS outbreak in a teaching hospital. CMAJ. 2003; 168: 1245-51.

[59] Lim S, Kim E, Kim A, Lee H, Choi H, Yang S. Nutritional Factors Affecting Mental Health. Clinical Nutrition Research [Internet]. 2016; 5(3): 143. 
[60] Capio C, Sit C, Abernethy B. Physical Well-Being. Encyclopedia of Quality of Life and Well-Being Research [Internet]. 2014; 4805-4807.

[61] PS, Shahid M. Work from Home during Covid 19: Employees Perception and Experiences. Global Journal for Research Analysis [Internet]. 2020; 9(5): 1.

[62] International Labour Organization 2020. An employers' guide on working from home in response to the outbreak of COVID-19. Geneva. 2021; 19.

[63] Xiao Y, Becerik-Gerber B, Lucas G, Roll S. Impacts of Working from Home During COVID-19 Pandemic on Physical and Mental Well-Being of Office Workstation Users. Journal of Occupational \& Environmental Medicine [Internet]. 2020; 63(3): 181-190.

[64] Asmundson G, Taylor S. Coronaphobia: Fear and the 2019-nCoV outbreak. Journal of Anxiety Disorders [Internet]. 2020; 70: 102196.

[65] Rožman M, Tominc the physical, emotional and behavioral symptoms of health problems among employees before and during the COVID-19 epidemic. Employee Relations: The International Journal [Internet]. 2021; ahead-of-print (ahead-of-print): 14-16.

[66] Grocke-Dewey M, Hardison-Moody A, Haynes-Maslow L, Maras S, Webber E, Andress L et al. Examining the relationship between physical activity and mental health during the COVID-19 pandemic across five U.S. States. Preventive Medicine Reports [Internet]. 2021; 24: 101537.

[67] Magnavita N, Soave P, Antonelli M. Prolonged Stress Causes Depression in Frontline Workers Facing the COVID19 Pandemic. A Repeated Cross-Sectional Study. [Internet]. 2021; 1.

[68] Evanoff B, Strickland J, Dale A, Hayibor L, Page E, Duncan J et al. Work-Related and Personal Factors Associated With Mental Well-Being During the COVID-19 Response: Survey of Health Care and Other Workers. Journal of Medical Internet Research [Internet]. 2020; 22(8): e21366.

[69] Norström F, Waenerlund A, Lindholm L, Nygren R, Sahlén K, Brydsten A. Does unemployment contribute to poorer health-related quality of life among Swedish adults? BMC Public Health [Internet]. 2019; 19(1): 1-6.

[70] Drake R, Sederer L, Becker D, Bond G. COVID-19, Unemployment, and Behavioral Health Conditions: The Need for Supported Employment. Administration and Policy in Mental Health and Mental Health Services Research [Internet]. 2021; 48(3): 388.

[71] Organisation for Economic Co-operation and Development. Tackling the mental health impact of the COVID-19 crisis: An integrated, whole-of-society response [Internet]. 2021; 7.

[72] Mojtahedi D, Dagnall N, Denovan A, Clough P, Hull S, Canning D et al. The Relationship between Mental Toughness, Job Loss, and Mental Health Issues during the COVID-19 Pandemic. Frontiers in Psychiatry [Internet]. 2021; 11: 12 .

[73] Griffiths D, Sheehan L, van Vreden C, Petrie D, Grant G, Whiteford P et al. The Impact of Work Loss on Mental and Physical Health during the COVID-19 Pandemic: Baseline Findings from a Prospective Cohort Study. Journal of Occupational Rehabilitation [Internet]. 2021; 457-460.

[74] Yao R, Wu W. Mental Disorders Associated with COVID-19 Related Unemployment. Applied Research in Quality of Life [Internet]. 2021; 16.

[75] Alradhawi M, Shubber N, Sheppard J, Ali Y. Effects of the COVID-19 pandemic on mental well-being amongst individuals in society- A letter to the editor on "The socio-economic implications of the coronavirus and COVID19 pandemic: A review". International Journal of Surgery [Internet]. 2020; 78: 147-148.

[76] Patel P, Rietveld C. The impact of financial insecurity on the self-employed's short-term psychological distress: Evidence from the COVID-19 pandemic. Journal of Business Venturing Insights [Internet]. 2020; 14: e00206.

[77] Wolfe M, Patel everybody hurts: Self-employment, financial concerns, mental distress, and well-being during COVID-19. Journal of Business Venturing Insights [Internet]. 2021; 15: 11-12.

[78] Mathew N, Deborah I, Karonga T, Rumbidzai C. The impact of COVID-19 lockdown in a developing country: narratives of self-employed women in Ndola, Zambia. Health Care for Women International [Internet]. 2020; 41(11-12): 1374-1377. 
[79] Dores AR, Carvalho IP, Burkauskas J, Simonato P, De Luca I, Mooney R, Ioannidis K et. al. Exercise and Use of Enhancement Drugs at the Time of the COVID-19 Pandemic: A Multicultural Study on Coping Strategies During Self-Isolation and Related Risks. Frontiers in Psychiatry [Internet]. 10 Mar 2021; 12: 165.

[80] Finlay JM, Kler JS, O’Shea BQ, Eastman MR, Vinson YR, Kobayashi LC. Coping During the COVID-19 Pandemic: A Qualitative Study of Older Adults across the United States. Front Public Health [Internet]. 7 Apr 2021; 9: 643807.

[81] Ogueji IA, Okoloba MM, Ceccaldi BMD. Coping strategies of individuals in the United Kingdom during the COVID19 pandemic. Current Psychology [Internet]. 03 Jan 2021

[82] Lara R, Fernandez-Daza M, Zabarain-Cogollo S, Olivencia-Carrión MA, Jimenez-Torres M, Olivencia-Carrión MD, Ogallar-Blanco A, Godoy-Izquierdo D. Active Coping and Anxiety Symptoms during the COVID-19 Pandemic in Spanish Adults. International Journal of Environmental research and Public Health [Internet]. 4 Aug 2021; 18(16): 8240.

[83] Priyanka, Rasania SK. A cross--sectional study of mental wellbeing with practice of yoga and meditation during COVID-19 pandemic. Journal of Family Medicine and Primary Care [Internet]. 29 Apr 2021; 10(4): 1576-1581.

[84] Ejiri M, Kawai H, Kera T, Ihara K, Fujiwara Y, Watanabe Y, Hirano H, Kim H, Obuchi S. Exercise as a coping strategy and its impact on the psychological well-being of Japanese community-dwelling older adults during the COVID19 pandemic: A longitudinal study. Psychology of Sport and Exercise [Internet]. Nov 2021; 57: 102054.

[85] Bartos LJ, Funes MJ, Ouellet M, Posadas MP, Krägeloh C. Developing Resilience During the COVID-19 Pandemic: Yoga and Mindfulness for the Well-Being of Student Musicians in Spain. Frontiers in Psychology [Internet]. 21 Apr 2021; 12: 642992.

[86] Nagarathna R, Anand A, Rain M, Srivastava v. Sivapuram MS, Kulkarni R, Ilavarasu J, Sharma MNK, Singh A, Nagendra HR. Yoga Practice Is Beneficial for Maintaining Healthy Lifestyle and Endurance Under Restrictions and Stress Imposed by Lockdown During COVID-19 Pandemic. Frontiers in Psychiatry [Internet]. 22 Jun 2021 ; 12: 878 .

[87] Diamond R, Waite F. Physical activity in a pandemic: A new treatment target for psychological therapy. Psychology and Psychotherapy: Theory, Research and Practice [Internet]. 25 Jun 2020; 94(2): 357-364.

[88] Morales-Rodriguez FM. Fear, Stress, Resilience and Coping Strategies during COVID-19 in Spanish University Students. Sustainability [Internet]. 23 Apr 2021; 13(11): 5824.

[89] Celestine N. What Is Mental Contrasting and How Can We Benefit From It? PositivePsychology [Internet]. 11 Mar 2021.

[90] Brodersen G, Oettingen G. Mental Contrasting of a Negative Future with a Positive Reality Regulates State Anxiety. Frontiers in Psychology [Internet]. 20 Sept 2017; 8: 1596.

[91] Oettingen G, Marquardt MK, Gollwitzer PM. Mental contrasting turns positive feedback on creative potential into successful performance. Journal of Experimental Social Psychology [Internet]. Sept 2012; 48(5): 990-996.

[92] Hearon BA, Beard C, Kopeski LM, Smits JAJ, Otto MW, Björgvinsson T. Attending to Timely Contingencies: Promoting Physical Activity Uptake among Adults with Serious Mental Illness with an Exercise-For-Mood vs. an Exercise-For-Fitness Prescription. Behavioral medicine [Internet]. 01 Feb 2017; 44(2): 108-115.

[93] Hood B, Jelbert S, Santos LR. Benefits of a psychoeducational happiness course on university student mental wellbeing both before and during a COVID-19 lockdown. Health Psychology Open [Internet]. 17 Mar 2021.

[94] Akena D, Kiguba R, Muhwezi WW, Kwesiga B, Kigozi G, Nakasujja N, Lukwata H. The effectiveness of a psychoeducation intervention on mental health literacy in communities affected by the COVID-19 pandemic-a cluster randomized trial of 24 villages in central Uganda-a research protocol. Trials [Internet]. 13 Jul 2021.

[95] Shorey S, Chan SWC, Chong YS, He HG. A randomized controlled trial of the effectiveness of a postnatal psychoeducation programme on self-efficacy, social support and postnatal depression among primiparas. Journal of Advanced Nursing [Internet]. 15 Dec 2014; 71(6): 1260-1273.

[96] Huffman EM, Athanasiadis DI, Anton NE. Haskett LA, Doster DL, Stefanidis D, Lee NK. How resilient is your team? Exploring healthcare providers' well-being during the COVID-19 pandemic. The American Journal of Surgery [Internet]. Feb 2021; 221(2): 277-284.

[97] Matiz A, Fabbro F, Paschetto A, Cantone D, Paolone AR, Crescentini C. Positive Impact of Mindfulness Meditation on Mental Health of Female Teachers during the COVID-19 Outbreak in Italy. International Journal of Environmental research and Public Health [Internet]. 4 Sept 2020; 17(18): 6450. 
[98] Liu L. Examining the Usefulness of Mindfulness Practices in Managing School Leader Stress During COVID-19 Pandemic. Journal of School Administration Research and Development [Internet]. 2020; 5(1).

[99] Bäuerle A, Graf J, Jansen C, Musche V, Schweda A, Hetkamp M, Weismüller B, Dörrie N, Junne F, Teufel M, Skoda EM. E-mental health mindfulness-based and skills-based 'CoPE It' intervention to reduce psychological distress in times of COVID-19: study protocol for a bicentre longitudinal study. BMJ open [Internet]. 13 Aug 2021; 10(8): e039646.

[100] Freligh CB, Debb SM. Nonreactivity and Resilience to Stress: Gauging the Mindfulness of African American College Students. Mindfulness [Internet]. 31 Jul 2019; 10: 2302-2311.

[101] Accoto A, Chiarella SG, Raffone A, Montano A, de Marco A, Mainiero F, Rubbino R, Valzania A, Conversi D. Beneficial Effects of Mindfulness-Based Stress Reduction Training on the Well-Being of a Female Sample during the First Total Lockdown Due to COVID-19 Pandemic in Italy. Int. J. Environ. Res. Public Health [Internet]. 21 May 2021; 18(11): 5512.

[102] Smirmaul BPC, Chamon RF, de Moraes FM, et al. Lifestyle Medicine During (and after) the COVID-19 Pandemic. American Journal of Lifestyle Medicine [Internet]. 2021; 15(1): 60-67.

[103] Beukes EW, Onozuka J, Brazell TP, Manchaiah V. Coping with Tinnitus during the COVID-19 Pandemic. American Journal of Audiology [Internet]. 14 Jun 2021.

[104] Beukes EW, Baguley DM, Jacquemin L, et al. Changes in Tinnitus Experiences during the COVID-19 Pandemic. Front Public Health [Internet]. 5 Nov 2020; 8: 592878.

[105] McKenna L, Marks EM, Hallsworth CA, Schaette R. Mindfulness-Based Cognitive Therapy as a Treatment for Chronic Tinnitus: A Randomized Controlled Trial. Psychother Psychosom [Internet]. 2017.

[106] Okabe-Miyamoto K, Lyubomirsky S. Social Connection and Well-Being during COVID-19. World Happiness Report [Internet]. 20 Mar 2021.

[107] Logel C, Oreopoulos P, Petronijevic U. Experiences and Coping Strategies of College Students during the COVID19 Pandemic. National Bureau of Economic Research. May 2021.

[108] Ogueji IA, Okoloba MM, Demoko Ceccaldi BM. Coping strategies of individuals in the United Kingdom during the COVID-19 pandemic. Curr Psychology [Internet]. 3 Jan 2021.

[109] Moore K, March E. Socially Connected during COVID-19: Online social connections mediate the relationship between loneliness and positive coping strategies. Research Square [Internet]. 22 Jun 2020.

[110] Mariani R, Renzi A, Di Trani Mi, Trabucchi G, Danskin K, Tambelli R. The Impact of Coping Strategies and Perceived Family Support on Depressive and Anxious Symptomatology during the Coronavirus Pandemic (COVID-19) Lockdown. Psychiatry [Internet]. 13 Nov 2020; 11: 1195.

[111] Kaniasty K. Predicting social psychological well-being following trauma: The role of post disaster social support. Psychological Trauma: Theory, Research, Practice, and Policy [Internet]. 2012; 4(1): 22-33.

[112] Mheidly N, Fares MY, Fares J. Coping With Stress and Burnout Associated With Telecommunication and Online Learning. Frontiers in Public Health [Internet]. 11 Nov 2020; 8: 672.

[113] June LN, June SA. Initial Real Time Coping by African American Christians during the Coronavirus Pandemic (COVID-19). Journal of Pastoral Care \& Counseling [Internet]. 29 Jun 2021; 75(3): 179-187.

[114] Hamilton JB, Best NC, Barney TA, Worthy VC, Philips NR. Using Spirituality to Cope with COVID-19: the Experiences of African American Breast Cancer Survivors. Journal of Cancer Education [Internet]. 17 Feb 2021.

[115] Kahambing JGS. Psychosocial wellbeing and stress coping strategies during COVID-19 of social workers in Southern Leyte, Philippines. Asian J Psychiatr. 2021; 62: 102733.

[116] Buenaventura RD, Ho JB, Lapid MI. COVID-19 and mental health of older adults in the Philippines: a perspective from a developing country. Cambridge University Press; International Psychogeriatrics [Internet]. 30 Apr 2020; 32(10): 1129-33.

[117] Vitorino LM, Low G, Vianna LAC. Linking Spiritual and Religious Coping With the Quality of Life of CommunityDwelling Older Adults and Nursing Home Residents. Gerontol Geriatr Med [Internet]. 11 Jul 2016; 2: 2333721416658140. 
[118] Kappel S, Schmitt O, Finnegan E, Fureix C. Learning from lockdown - Assessing the positive and negative experiences, and coping strategies of researchers during the COVID-19 pandemic. Applied Animal Behaviour Science [Internet]. Mar 2021; 236: 105269.

[119] Teng-Calleja M, Caringal-Go JF, Manaois J, Isidro MQ, Zantua RM. Examining Organizational Response and Employee Coping Behaviors amid the COVID-19 Pandemic. J Beh Scie [Internet]. 27 Sep 2020; 15(3): 34-0.

[120] Babicka-Wirkus A, Wirkus L, Stasiak K, Kozłowski University students' strategies of coping with stress during the coronavirus pandemic: Data from Poland. PLOS ONE [Internet]. 26 Jul 2021; 16(7): e0255041.

[121] Lunn PD, Timmons S, Julienne H, Belton CA, Barjaková M, Lavin C, McGowan F Using decision aids to support selfisolation during the COVID-19 pandemic. Psychology \& Health [Internet]. 03 Jul 2020; 36(2): 195-213.

[122] Frey MK, Chapman-Davis E, Glynn SM, Lin J, Ellis AE, Tomita S, Fowlkes RK, Thomas C, Christos PJ, Cantillo E, Zeligs K, Holcomb K, Blank SV. Adapting and avoiding coping strategies for women with ovarian cancer during the COVID-19 pandemic. Gynecologic Oncology [Internet]. 2 Feb 2021; 160(2): 492-498.

[123] Ammar A, Brach M, Trabelsi K, Chtourou H, Boukhris O, Masmoudi L, Bouaziz B, Bentlage E, How D, Ahmed M, Müller P, Müller N, Aloui A, Hammouda O, Paineiras-Domingos LL et. al. Effects of COVID-19 Home Confinement on Eating Behaviour and Physical Activity: Results of the ECLB-COVID19 International Online Survey. Nutrients [Internet]. 22 May 2020; 12(6): 1583.

[124] Cherikh F, Frey S, Bel C, Attanasi G, Alifano M, Iannelli A. Behavioral Food Addiction During Lockdown: Time for Awareness, Time to Prepare the Aftermath. Obes Surg [Internet]. 13 May 2020; 30(9): 3585-3587.

[125] Rolland B, Haesebaert F, Zante E, Benyamina A, Haesebaert J, Franck N. Global Changes and Factors of Increase in Caloric/Salty Food Intake, Screen Use, and Substance Use During the Early COVID-19 Containment Phase in the General Population in France: Survey Study. JMIR Public Health Surveill [Internet]. 18 Sept 2020; 6(3): e19630.

[126] Litwin R, Goldbacher EM, Cardaciotto L. Negative emotions and emotional eating: the mediating role of experiential avoidance. Eat Weight Disord [Internet]. 2017; 22: 97-104.

[127] Di Renzo L, Gualtieri P, Cinelli G, Bigioni G, Soldati L, Attinà A, Bianco FF, Caparello G, Camodeca V, Carrano E, Ferraro S, Giannattasio S, Leggeri C, Rampello T, Lo Presti L, Tarsitano MG, De Lorenzo A. Psychological Aspects and Eating Habits during COVID-19 Home Confinement: Results of EHLC-COVID-19 Italian Online Survey. Nutrients [Internet]. 2020; 12(7): 2152.

[128] Al-Musharaf S. Prevalence and Predictors of Emotional Eating among Healthy Young Saudi Women during the COVID-19 Pandemic. Nutrients [Internet]. 2020; 12(10): 2923.

[129] Cummings JR, Ackerman JM, Wolfson JA, Gearhardt AN. COVID-19 stress and eating and drinking behaviors in the United States during the early stages of the pandemic. Appetite [Internet]. 01 Jul 2021; 162: 105163.

[130] Gonçalves PD, Moura HF, do Amaral RA, Castaldelli-Maia JM, Malbergier A. Alcohol Use and COVID-19: Can we predict the Impact of the Pandemic on Alcohol Use Based on the Previous Crises in the 21st Century? A Brief Review. Front Psychiatry [Internet]. 18 Dec 2020; 11: 581113.

[131] Romano I, Patte KA, de Groh M, Jiang Y, Wade TJ, Bélanger RE, Leatherdale ST. Substance-related coping behaviours among youth during the early months of the COVID-19 pandemic. Addictive Behaviors Reports [Internet]. Dec 2021; 14: 100392. 